\title{
Navigation in Space-Time as the Basis for Information Modeling
}

\author{
Alina Paranina \\ Herzen State Pedagogical University of Russia, St-Petersburg, Russia \\ Email: galina_paranina@mail.ru \\ Received 26 May 2014; revised 29 June 2014; accepted 11 July 2014 \\ Copyright (C 2014 by author and Scientific Research Publishing Inc. \\ This work is licensed under the Creative Commons Attribution International License (CC BY). \\ http://creativecommons.org/licenses/by/4.0/

(c) (i) Open Access

\begin{abstract}
The article presents the author's concept of information modeling of the world, based on the leading role of solar navigation (orientation in space-time by the sun). The concept was developed in the course of comprehensive research on the main patterns of use of information resources (semiotics) during the exploration of nature of geographical space by humans. The objects of the study were the monuments of ancient material culture of European Russia and Southern Siberia. The applied field research methods include survey, description, observation, work with maps and Earth remote sensing, as well as methods of mathematical, conceptual modeling and mapping. Theoretical analysis is based on the theory of reflection and systemic and chorological approach, methodological statements of historical geography by V.I. Paranin.
\end{abstract}

\section{Keywords}

Navigation, Information, Semiotics, Geographical Space, Model of the World

\section{Introduction}

The urgency of developing geographical aspects of the theory of information is determined by a combination of environmental and economic problems, the growing volume of information in semantically indefinite Humanities and need for continuous improvement of navigation in the expanding information space. Identification of coding algorithms, retention, transfer and transformation of information in natural and socio-natural systems not only allows us to reconstruct the stages of the evolution of information model of the world, but also opens the prospect of optimizing relationships of humans and nature and taking into account the nature of the organization and self-organization processes. The definition of "information” as an attribute of matter and organized diversity of systems fits to solve the abovementioned problems (Paranina, 2005).

Our study of information processes in geographic space has a purpose to examine samples and identify ac- 
tions algorithms of universal organizing factor-the flow of matter, energy and information. One of the objectives of this work is generalization of the results obtained in three main areas: 1). Variety of structures and semiotic resources of natural systems; 2). Reflection of natural processes in the sign and knowledge; 3). Impact of world's information modeling on the social and cultural paradigm and organization of developed space.

It is well known that the energy of the sun maintains more than $90 \%$ of all the processes on the surface of the Earth. Sunlight at different latitudes of the globe at different angles creates geographical zoning of the Earth, which is evident in every aspect of living and inanimate nature, determining the quantity, quality and dynamics of material and energy resources. However, the mode of surface illumination provides all life forms with another important resource-information about the space-time development, whose adequate reflection guarantees survival and development. Comparative analysis of the semiotics of natural processes shows that the most reliable guide to navigation in geographic space are parameters of supersystem, as they are relatively more stable- this explains the widespread use of astronomical knowledge in ancient times, when humans did not maintain settled lifestyle, and the infrastructure of regional and transcontinental communications did not have the current level of development. Analysis of primitive graphics conducted by V.A. Frolov has indicated signs of astronomical and mathematical knowledge (Frolov, 1992).

Observation of sunrise/sunset and fixing of astronomically significant points on the horizon line by establishing visual communication with elements of the observation site, its near and distant surroundings, has been called direct sighting in horizontal astronomical observatory. Depth of tradition, development and application of this technology are reflected by a diversity of monuments of megalithic culture (Hawkins, 1977). But these marine navigation methods initially had a limited use (only on shore), so a more developed technology was backsight movement of the sun shade on a vertical or inclined Polaris subject—gnomon that were used before the advent of modern navigation tools. Analysis of the descriptions and images of sundial calendars in literature, spoken folk tradition, studies on the history of optics (Paranina, 2010; Sundial and calendar systems..., 1985; Stafeev \& Tomilin, 2006) showed that the gnomon could be a staff, spear, rod, scepter, mast, anchor, as well as the human's height in correlation with the measured length of foot and even shade of the palm in relation to the length of one of the fingers. Calculations of the annual amount of shadow of the gnomon at different latitudes showed that encoding of motion of the Sun through the shadow of the gnomon geometry paves the way for the formation of character, genetically related to the diversity of incarnations of space-time. Versatile determining of the quality of the object referred to by its position in space-time contributed to development of this form of information encoding. In contemporary research on semiotics a method of comparative analysis of different quality characters as elements—-within the established system—is used.

The question of navigational self-organization of territorial systems based on structural flows was developed in the studies of the doctor of geographical sciences V.I. Paranin. The author based the systematic analysis of the structure and information of the territory on original interpretation of ancient geographical names (toponyms) as markers of their position in the integral system. Navigation reading method of names helped the author to correctly localize the island Rus from Arab sources as modern Karelian Isthmus, lapped by the waters of Lake Ladoga and the Gulf of Finland, and two rivers - the Neva and once affluent Vuoksa (Paranin, 1990). Application of systems and information modeling in the Eurasian space allowed V.I. Paranin to determine the exact address of the "lost" objects as Meotida and Rhipaean mountains, Cimmerians and other peoples described in the sources of ancient times (Paranin, 1998). In a series of studies V.I. Paranin substantiated northern origin of popular in ancient time cult of Apollo-god of the sun. Our research of northern labyrinth and other ancient sites in 2009-2012 showed that they are astronomical instruments of orientation by the Sun (Paranin \& Paranina, 2009; Paranina \& Paranin, 2009; Paranina, 2010). It was another material confirmation of the concept of historical geography by V.I. Paranin.

The proposed information model of the world, based on the provisions of the historical geography of V.I. Paranin and our comprehensive studies of navigation allow us to consider all the achievements of culture, as a result of conversion of solar energy.

\section{Space-Time Structure of the Information Model of the World}

The basic units of the information model of the world (IMW) reveal different aspects and levels of modeling of space-time (Figure 1): the first basic level—-the navigation, creates a spatial and conceptual framework of IMW; second modeling level—reflects semiotic, linguistic, cartographic, toponymic, mythological units that encode, 


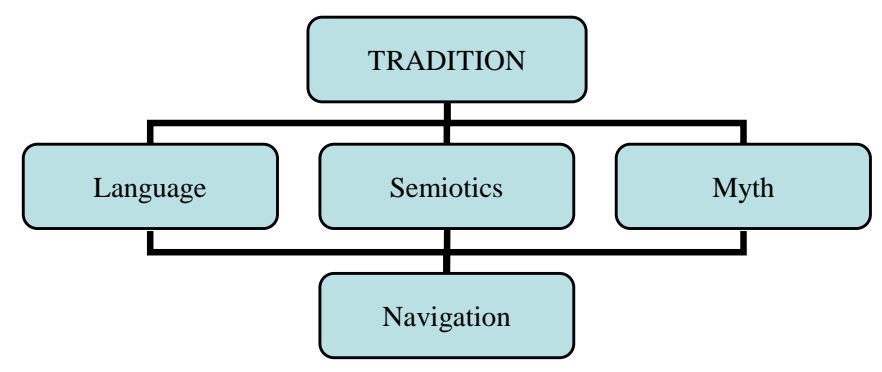

Figure 1. The structure of the information model of the world.

duplicate and replicate vital navigational information; and the crown of the model—a tradition that serves as the selection and storage of proven information to maintain the continuity of Life, including the Renaissance. Basic processes and phenomena form the reference benchmarks of fundamental concepts, the meaning of which is priceless, and therefore sacred, and their shape is less exposed to other transformation. Structure flow, which maintained sustainability of this model throughout the history of our civilization, was a continuous practical use of sunlight to ensure the order (Paranina, 2010).

\subsection{First Level of Modeling of Space-Time: The Development of Technology and Geography of Navigational Objects}

The first step in the implementation of information navigation in geographic space allocation are sacred landscapes - nature areas that provide convenience and reliability of observation to record information about the order of the space-time (linear structure of the landscape and its components: the tectonic cracks and fissures, landforms and hydrographic features that coincide with astronomically significant azimuths at this latitude). The next step are creating markers that distinguish these objects and information contained in them in the surrounding landscape (petroglyphs, chain of natural and man-made objects in the position or shape of which is obviously the application of additional energy of non-natural source). Accuracy of the received information and the position of the main areas of human movement can strengthen and develop navigation function of area, the development of tools and the use of new technologies. Stages of navigation improvement of area are well disclosed in the form and planigraphy of local natural and cultural heritage, as a result of analysis of the characteristics of their location in the landscape, regional and global geographic space. Here are some examples.

Local objects and networks. Calendar subjects of petroglyphs of Staraya Zalavruga (river Vyg, White Sea coast, age 6000 years), have a direction W-E, as well as cracks in the rocks on which they are applied, some areas are marked with stone blocks. Main panel of petroglyphs Kalbak Tash (river Chuya, Altai Mountains) is located on the step in the relief oriented W-E-that allows you to use these facilities for determining days of spring and fall equinoxes, dividing the year in winter and summer. Figure of Bes in Onega petroglyphs frames a crack in the rock, whose azimuth corresponds to the sunrise at the summer and sunset in the winter solstice. Visually interconnected megalithic objects on the Kola Bay hills surrounding the city of Murmansk (megalith in City Park, trilit-Raven Stone and seids on Stone planum) make it possible to determine the direction of W-E and the direction of the geographic meridian on which the boundaries of polar days and nights are fixed.

The space of later objects is also oriented on the Sun. Salbyksky mound field of Tagar time in Khakassia and megalithic complex with revered stone of St. Paraskeva Friday in the Leningrad region are located on the elements of the relief-oriented on SE-NW by natural processes: water erosion in pre-sloping part of Salbyksky mountain valleys and intensity of tectonic processes in the deepest valley Cheremenetskiye lakes (SW shore of lake Vrevo). Linear elements of landscape pattern in both cases correspond to the azimuth of sunrise in winter/sunset in summer solstice, and the main sacred objects repeat the main and add other calendar direction: WE, NE, SE (Paranina \& Marsadolov, 2010).

Many sites may use the forward and back sighting, but some are decrypted only by using the shadows. Thus, only the use of the gnomon showed that the stone labyrinths of the White Sea-are solar calendars, clocks and compasses (Paranin \& Paranina, 2009; Paranina \& Paranin, 2009; Paranina, 2010). The installation position of gnomon in the figure of stone labyrinth, omphale (small stele), prominent stone crossing spirals or other way, azimuths of astronomically significant directions - the equinoxes and solstices, marked their entry points and end points or spirals around a labyrinth of objects (pile or rows of stones), the length of the midday shadows 
fixed diameters of arcs, central and peripheral of which (or northern addition) correspond to the shortest and longest midday shadows of the year.

Usual location of labyrinths on the banks is explained by provision of the most exact azimuths on the horizon, which is a surface of the sea. Accumulation of more than 30 labyrinths in a small space of Bolshoy Zayatsky Island $\left(1.25 \mathrm{~km}^{2}\right)$ can be regarded as a local astronomical and geodetic network. The selection of optimal sites for viewing different azimuths can explain the proximity and combination of instruments in other regions, particularly in mountainous areas.

Location of solar orientation tools in regional space was not accidental: they can be placed on the same line or along the waterway. The ability to use stone labyrinths and other megalithic sites in the quality of astronomical instruments allows us to consider the whole set of them in the North as a regional navigation network. Reason for diversity of forms of the northern labyrinths, especially above and below the Arctic Circle-is, first and foremost, increased in comparison with other latitudes dynamic astronomical orientations in space and time. You can navigate using the template only if you move along parallel—at the same latitude, while moving in the northern or southern directions it is necessary to make substantial amendments to the latitude. Astronomical figures of polar latitudes show greater sensitivity to changes in tilt of the earth and other cosmo-planetary parameters during the long-term rhythms. Given the increased dynamism of polar latitudes, Arctic borders in ancient times were held between $50^{\circ}$ and $60^{\circ}$. The second most important fact in determining the uniqueness of each labyrinth pattern is the shape of the physical surface of the Earth (topography of the area and the nature of horizons). Any deviation from the astronomical horizon line lead to a shift of points of sunrise/sunset, and hence change the magnitude of these azimuths. A calendar tradition played a specific role and defined a choice of astronomical highlight climaxes as the beginning of the year.

Regional toponyms often contain an indication of the color, as a feature of location of parts in a spatial system (Paranin, 1990). Elements of waterways can have marking by toponyms with a single basis, often denoting the concept of "light", such as vol/val (Volga, Valdai, Volkhov, Valaam and toponyms in Karelia), gol/kol (Pas-de-Calais, England, Holland, Kola peninsula), on (Onega lake and river). In Karelia and the Kola Peninsula there are hydronyms including base tul, which are associated with mysterious "last Thule", referred to in ancient times as the limit of the land in the North. It is interesting that in English the word refers to both the tool and part of the body, associated with gnomon.

Popularity of solar navigation is explained by accessibility and sustainability of landmarks, versatile technology and powerful impact on the environment and people.

Global solar orientation system could use information resources and locations to consider the accumulated knowledge about the light conditions at different latitudes of the Earth. Analysis of the maps of the world shows that astronomically sensitive areas-border zone lighting (tropics and polar circles) coincide with the regions, which are characterized by a large number of sunny days per year, which explains the development of solar cults. Most stable sunny weather is in the tropics, where high atmospheric pressure is maintained throughout the year-these regions of the world are known for their monuments toponyms: Egypt, Mexico, Peru and others. Sacredness, monumentality and dry climate contributed to their preservation. Extracontinental dry climate in the center of Eurasia is the natural foundation of the development of the solar cult in the territories, now belonging to an area of "lunar" cultural preferences. Proof of this are the megalithic monuments of Tagar time, especially Okunev culture in Khakassia, dating back to 2000 BC, toponyms, and ancient petroglyphs, solar bulls, circles, concentric and spiral labyrinths in Sayano-Altai. Special feature of the polar zone is that in summer, during the active business activities, all reference points of the night sky are excluded from observations-the polar day and white nights make them difficult to be noticed. Another feature of this region is that within a year the cosmographic situation in the northern (and southern) polar circle provides possibilities, which do not exist anywhere on the planet: "Only on these special parallels once a day horizon crosses simultaneously all the zodiacal constellations. Plane of the true horizon and the ecliptic coincide at 18 hours sidereal time” (Smirnov, 2011: p. 127).

Location of several major sacred sites of Asia at latitude $52^{\circ}$, and Stonehenge and Mostischenskogo labyrinth$51^{\circ} \mathrm{N}$ are worth mentioning. According to a leading researcher of Russian Academy of Sciences S.S. Smirnov, the location on the same latitude of the known number of cities - the ancient cultural centers on the largest rivers in Europe was not accidental: reason for the popularity of the $51^{\text {st }}$ parallel in antiquity could be that it is one of the borders of the seven climates-areas with different modes of sunlight, whose description is known from the studies of scholars of ancient Babylon $\left(90^{\circ} / 7=12.857^{\circ}, 12.857^{\circ} \times 4=51.4^{\circ}\right)$ [8]. This fact was a serious argument to highlight the spatial boundaries and, as we see, was maintained in relatively remote regions, representing 
the expression of a single paradigm in navigation.

\subsection{The Second Level of Modeling Is Coding, Preservation and Transfer of Navigation Information in the Abstract and Figurative-Symbolic Form}

The development of this level of technology required to use backsight by shadows-all double-substituted lighting objects and, in fact, the very light. The diagram of shadow of the gnomon for the year represents a Labrys-Bilateral horned ax of gods - creators of the world (Figure 2).

According to one definition, a labyrinth is the house of Labrys. However, on the same basis you can draw graphics and other sacred images of Time: Lotus - the day of gods and equivalent of year, the many-armed Shiva, whose six hands correspond to azimuths division of year to the astronomical seasons (sunrise/sunset at the equinoxes and solstices). Marks of the position of heights of gnomon's shadows per day contain a fork and consistent forms of drawing creates a graph, comparable to widely distributed in the ancient art of various attributes of the gods according to structure and contour: the wings of birds (individual lines represent feathers), caudal fin of fish (lines represent fin rays), bulls horns (lines represent annual growth).

Thus, the encoding algorithm can be represented as a series of "natural process-sign-image." If you give a new definition of these concepts: sign is a graphical record of the natural process, image is an artistic interpretation of the sign, myth can be defined as the image-recording scene of a natural process. Most clearly these concepts work in the cosmogonic myths of ancient Egypt and other civilizations, organized under the laws of the solar and lunar-solar calendar. Navigational reading of myths reveals new depths of their forgotten content: apple of knowledge (labyrinth similar to the apple in the cross-section) measuring the time it deprives a person of the illusion of eternity, and the time spiral wound around the gnomon-body stands for serpent; the construction of the Tower of Babel is not an insane rampage of ambition and desire for knowledge (the higher the gnomonthe more accurate it is); spear and a rope near labyrinth images on ancient coins are weapon of survival in a fight with a horned monster, as well as they are essential tools for the construction of a solar calendar (horns-diagram of shadow, spear-gnomon, rope-a compass, a ruler, a primary material for drawing layout).

A sign is concrete in terms of content and abstract in terms of form. Image is available for mass knowledge, easily replicated and transmitted, but not for representatives of urban culture, divorced from nature, it is abstract in terms of content, as the astronomical instrument. Of course, the myth bears not only a description of the real nature of the process, but also an admixture of mysticism — as any attempt to describe the fullness of integrated but not fully understood process.

\subsection{The Third Level of Modeling-The Sacred Tradition}

No wonder that in ancient navigation objects and their semiotic interpretations reflected the evolution of the socio-cultural paradigm and the development of the tradition. We note some specific moments.

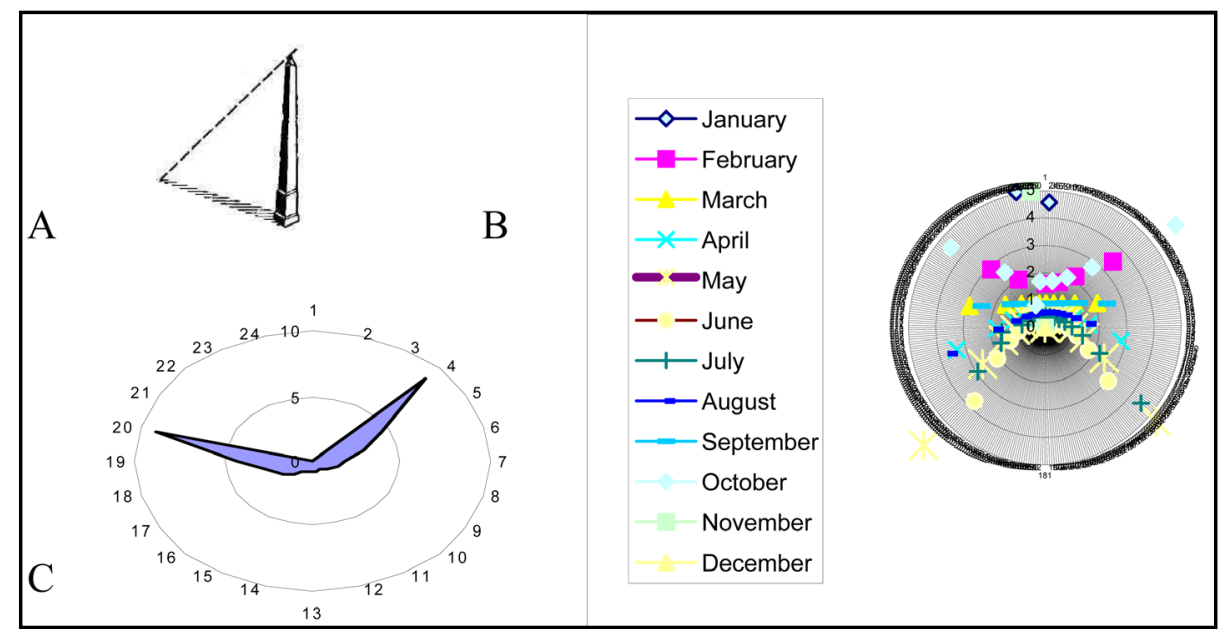

Figure 2. Gnomon (A) and geometry of its shadows: per day ((C), North at the bottom) and per year (B) (Paranina, 2010). 
For navigation in time a universal reference at all latitudes is the sunrise in the east and sunset in the west at the equinoxes, dividing annual cycle into two main halves-winter and summer. The reliability of this landmark is one of the reasons for veneration, mass and widespread use and conservation. Thus, deer stones and stelae in Khakassia with their edge and high side of plates indicate east, allowing you to use them as calendars and compasses. In the signs, a line EW has a horizontal position, and sacral complexes can be marked by paired elements (obelisks at temples of Ancient Egypt). Navigation by rise/set of day and night light by direct sighting with marks in relief, according to the established objects or notches on them, left many traces in IMW (in the dialectical paradigm of binary organization of the World, in terms of pairing of definitions yes/no, day/night, light/shadow, signs $1 / \mathrm{I}$ and $2 / \mathrm{Z} / \mathrm{S}$ ) and is used now (binary code).

Backsight system by the shadow of the gnomon (vertical object), changed the paradigm of thinking, having carried out a truly "paradigm shift": shadows at sunrise fall to the west and at sunset— to the east, moving during the day "clockwise", direction of recording signs from left to right originates from this point. Instrumental measurement of the sum of shadows with distinguishing of the exact middle of the day and astronomical climaxes of year gave signs W, M, $\Sigma$ and 3, and made gnomon a symbol of solar knowledge and the basis for the most important mythopoetic images: Mount Meru, the World Tree, the concepts of "Peace" and "Light". Rays converging to the top of the gnomon are the images of branches, and shadows, diverging from the base are the roots, although mythology also has "inverted" examples: in the hands of Varuna World Tree roots absorb the information and energy of the Cosmos, and branches and fruits are lowered to Earth. In this model of the World, the embodiment of causal relations in the system "Nature-Knowledge" can be noticed.

The navigation process through (g) nomon created a universal principle "die to be born", describing three basic positions of the Sun (Sunset, sunrise and culmination), methodology "cycling and reflection”, retaining its value, and M-concepts: scale as "mega”, divinely wise as Mitra, Medea, Melpomene, sacred as Mecca, on the central position-Midia, Meotida that probably also ensured sacredness, and terms related to the measurement and markers, including different in color chalk (white) (in Russian- - "mel”) and melanin (black).

One of the expressions of a new paradigm was the change of socio-political unit-from the "unity of significant parts" agreed with direct sighting, by the installation of objects in a circle (astronomical tool—cromlech, rotunda, symbolic model—a crown), to the idea of "nerve center" generating information on the order (tool—gnomon, symbol-Monomakh's Cap). Finally, attention to sign (geometry of shadows) diverted attention from the natural process, became the basis of the modeling of higher levels, led to the suppression of environmental mentality, forming the illusion of emancipation from Nature.

The most reliable guide in the space is direction to the north, and every day and universally it is determined by the direction of the shortest shadow at noon. Line N-S divides the space into two parts—east and west, associated with the two halves of the day path of the Sun and indicates that part of the horizon, where it is hidden "in the house." The direction of the north became the vertical axis (y), the concepts associated with the north "Nord", and the beginning of the order "ord-", "coordinates", as well as linguistic and graphical basis of the numeral " 4 " ("shadow of the gnomon", combined 21, where 2 is shadow and 1 is gnomon), the Russian letter "Ч". The Russian word "север" [sever] (North) also has a "twin" of objects, designated in all languages with root "se": second—2, Seth—god of shadows in Ancient Egypt, Selena—moon, which means the second (by priority of rise during the day), "sen" — a pronoun "you", i.e. second with respect to individuum, indicates by one, which is equivalent to the letter I in the Roman and Germanic languages, in others-the word "men" (center).

And finally, the base "ist"-IST, 123, in Ancient Egypt meant the name of the goddess, translated as "ancient”, and in the Indo-European languages—is a verb defined as "being”. Such concepts as "source", "history", "truth" originate from this base. A saying "Time puts everything in its place" helps to see a single semantic field of the abovementioned examples of word formation, and natural process that was obvious in the original base, should be logically considered as daily observed diurnal position of the Sun: sunrise, sunset, midday.

And now we, like our forefathers, no longer see a mystery in a saying, carved by an ancient Egyptian master on a Sais stone, where a statue of Isis was erected: "I am what was, what is and what will be".

\section{Conclusions}

Information model of the world based on the orientation in space-time showed its effectiveness during the study of a variety of problems, including:

-definition of the sacredness of the natural and cultural heritage through the implementation of a rational 
function - the primary purpose of their communication with the information life system;

-overcoming difficulties of semantic analysis in semiotics, linguistics, philology, culture and archeology, the cause of which is the failure of humanitarian research methods (analysis of man-made models in isolation from the natural processes reflected in these);

-evidence of widespread use of astronomical tools such as material evidence of the universal development of celestial navigation skills, which is the basis for toponimical marking of space and other provisions of the historical geography of V.I. Paranin.

Among the most exciting prospects for the application of navigation modeling of the world are comprehension of the order and initial sense of semiotic systems explored by humans, including language Nostratic basis. But a more important result of the use of the navigation model can be a correction of concepts of modern urban culture on the level of spiritual and material culture of human history and prehistory of the past. Probably, this is a chance to learn from the ancestors to see and understand the signs of nature, change our attitude towards the people who laid the foundation of our civilization. To understand the past is an opportunity to change ourselves, and therefore to change our future.

\section{References}

Paranin, V. I. (1990). Historical Geography of the Chronicle of Russia. Petrozavodsk: Karelia, 152 p.

Paranin, V. I. (1998). The History of the Barbarians. St. Petersburg: Ed. RGO, 284 p.

Paranin, R. V., \& Paranina, G. N. (2009). The Labyrinth: Orientation in Geographic Space and the Evolution of the Mark. Space Geocultural European North: The Genesis, Structure and Semantics. [Materials IV Pomeranian Readings on the Semiotics of Culture, 7-11 July 2009, Pinezhsky Reserve] Archangel: Pomorski Univ., 516-518.

Paranina, G. N. (2005). Geographical Aspects in the Study of Information Processes. The Regional and Sectoral Geographic Research, St. Petersburg: Univ. RGS, 62-65.

Paranina, G. N. (2010). Light in the Labyrinth: Time, Space, Information. SPb.: Asterion, 123 p.

Paranina, G. N., \& Paranin, R. V. (2009). Northern Labyrinths as Astronomical Instruments in Relation to Patterns of Mythology and Symbols of Culture. Society, Environment, Development, 4, 120-134.

Paranina, G. N., \& Marsadolov, L. S. (2010). Cultural and Natural Heritage as Information Resources Geo-Cultural Space. Development of Tourism in the Baltic the Region: Background, Current State and Prospects of the Conference with International Participation on 18-19 November 2010. Pskov Pskov State Pedagogical University, 24-27

Smirnov, S. S. (2011). Twelve Rays of the Star of St. Petersburg. Cosmography of the Northern capital. Time. Landscape. Culture. Materials of Conf. Seminar "Ethnocultural Geography and Semiotics of Geographical Space” of 2011 MY. 2, St. Petersburg.: Asterion, 126-129.

Sundial and Calendar Systems of the Peoples of the USSR (1985). Series "Problems of research of the Universe” Issue. 10, L.

Stafeev, S. K., \& Tomilin, M. E. (2006). Five Thousand Years of Optics: Prehistory. St. Petersburg. Politekhnika, 304.

Frolov, B. A. (1992). Primitive Graphics of Europe. M.: Nauka, 200 p.

Hawkins, J. (1977). Apart from Stonehenge. New York: Wiley, 268 p. 
Scientific Research Publishing (SCIRP) is one of the largest Open Access journal publishers. It is currently publishing more than 200 open access, online, peer-reviewed journals covering a wide range of academic disciplines. SCIRP serves the worldwide academic communities and contributes to the progress and application of science with its publication.

Other selected journals from SCIRP are listed as below. Submit your manuscript to us via either submit@scirp.org or Online Submission Portal.
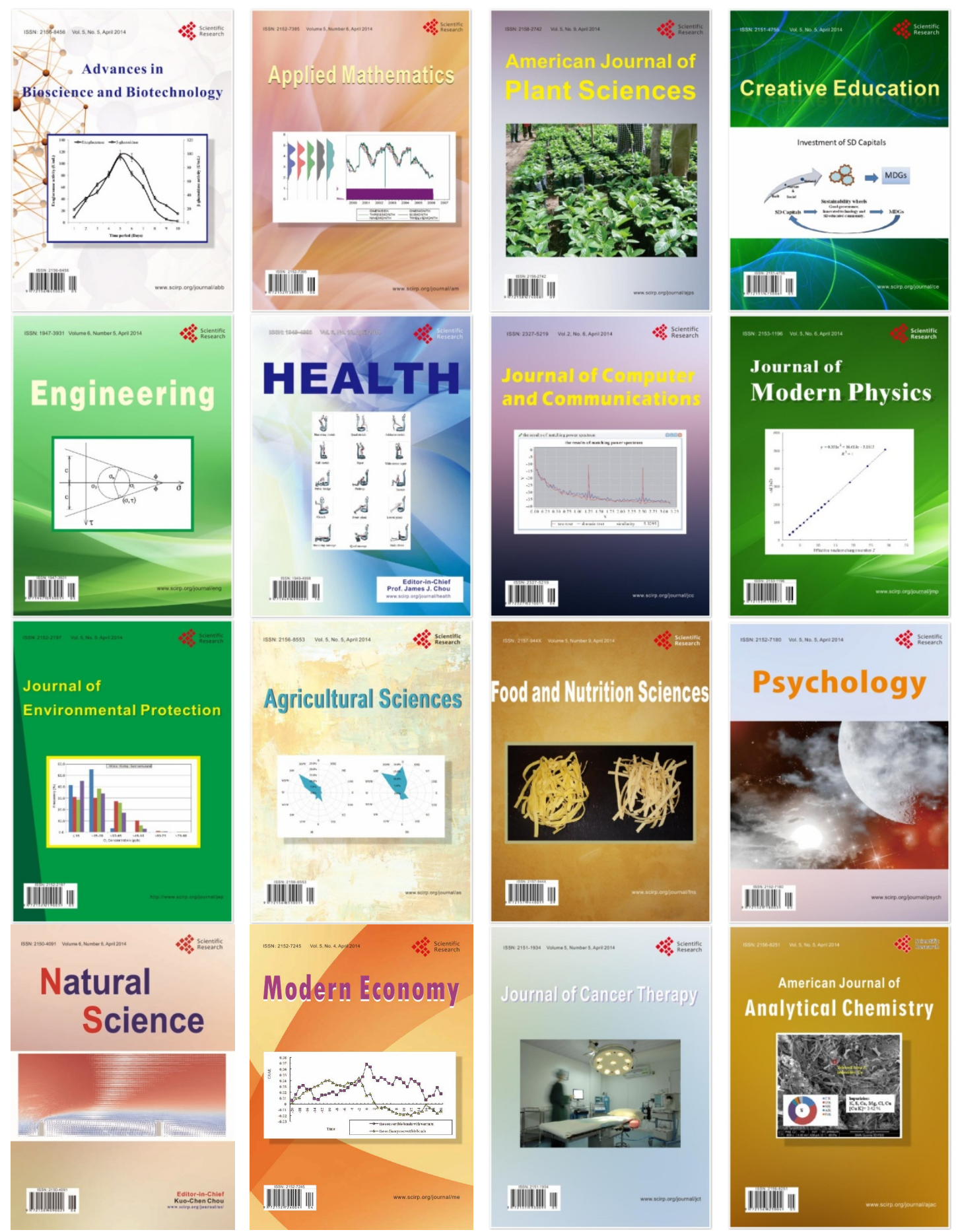